\title{
The effectiveness of health warning messages
}

Health warnings are an important part of any comprehensive strategy to reduce tobacco use, providing both the first and last lines of defence in the struggle against smoking and death. Ideally, health warnings should be the first thing smokers see before buying their cigarettes and the last thing they see before lighting up their cigarettes. In addition, health warnings should discourage youth from taking up smoking and should encourage those smokers contemplating quitting to do so.

Unfortunately, health warnings are almost invisible. On cigarette packets, they are found on one side or the other in relatively small print. In advertisements, they are usually found in a corner to which the eye is rarely drawn. Indeed, in comparison with looking at the rugged Marlboro Man, or that smooth character, Joe Camel, who would want to read a health warning?

Do we really known what we want to accomplish by using health warnings? Probably not. What we are really trying to do is to market health, and in so doing we have to think and act like a real company, using all available marketing tools. Unfortunately, we tend to assume that, because health warnings are so important, there is no need to market the information actively. Rather, we believe that smokers will find this information so interesting and convincing that, after reading it, they will change their behaviour. Consequently, we leave the marketing to the tobacco industry, which has continuously proven its ability to divert smokers' attention from these messages.

Any good marketeer will tell you that to market a product successfully, you have to communicate with your target audience. In doing this you have to identify your target audience; determine their ideas, beliefs, and impressions about the product; determine the desired response; design and develop the message; select the channels of communication to carry that message; determine the budget; and, most importantly, measure the impact of the message.

In their article evaluating health messages in cigarette advertisements, published in this issue of Tobacco Control, pp. 279-85, Fischer and colleagues have begun the process of test-marketing health warnings. They demonstrate that current health messages are "worn out" and need to be replaced. To their credit, they have actually identified and consulted with a target audience, namely adolescents, and developed two health warning messages that have meaning to this audience. In addition, as suggested above, they have developed measurement criteria for their messages.

Two critical questions should be looked at in conjunction with this study. First, what has been the experience in other countries with respect to health warnings? Second, what are the effects of changing parameters such as colour, size, and location?

Currently, there are three world leaders in the area of health messages: Thailand, Australia, and Canada. It is worth noting that all three have adopted the same approach in banning advertising and in requiring large health messages on cigarette packs.

Banning advertising makes it that much more difficult for cigarette manufacturers to market their products in ways counter to the health message. In addition, large warnings on cigarette packs, and additional information such as that proposed in Australia, ${ }^{1}$ provide an effective and inexpensive way, from the government's point of view, of reaching the smoker.

In Canada, the Tobacco Products Control Act (TPCA) came into force on 1 January $1989 .^{2}$ The Act banned advertising in all media and required manufacturers to place specific health messages on their packaging that was legible and in contrasting colours. While there has been some concern as to whether the current messages meet these requirements, there is ample evidence to suggest that these messages are being noticed and read.

A tobacco industry "mall-intercept" survey performed immediately after the introduction of the health warning messages in the summer of 1989 indicated that $95 \%$ of those people surveyed noticed the health warning message when shown a pack of cigarettes. ${ }^{3}$ This compared with the $82 \%$ who reported the brand name, while $81 \%$ found the health message to be either easy or very easy to pick out. ${ }^{3}$ While this survey is flawed and the results suspect, ${ }^{4}$ the fact that a message of gold letters on a cream background would elicit such a high response is important. The evidence seems to indicate that, initially, there was a high interest in the messages.

A more recent focus group study conducted by the Canadian government found that $90 \%$ of smokers read health warning messages, and $35 \%$ of them read the messages at least once a day. ${ }^{5}$ Smokers in this study reported that they read a health warning message, on average, 14 times per day. ${ }^{5}$ If these percentages are representative of all Canadian smokers, they suggest that a health warning message is read in Canada about 9.1 million times a day.

The results of this study also indicated that cigarette packs were a primary source of health information concerning tobacco (55\%), second only to television $(59 \%)$, and well ahead of newspapers at $17 \% .^{5}$ Consumer understanding $(98 \%)$ and acceptance $(86 \%)$ of the package warnings, and the importance $(78 \%)$ and meaningfulness $(75 \%)$ of the messages to them, were all high. ${ }^{5}$

Although this was a focus group study based on participants' self-reports, the results do suggest that the use of tobacco product packaging is a useful, effective, and inexpensive way of reaching Canadian smokers. Nevertheless, "wear-out" has been a primary concern. In order to prevent this from occurring, as well as for other reasons, new regulations were announced on 11 August 1993 that would increase the number of messages from four to eight and move the messages from the bottom $20 \%$ of the largest display surface of the pack to the top $25 \%$.

If one includes the $3-4 \mathrm{~mm}$ border which is also required, then the health messages will occupy between $35 \%$ and $45 \%$ of the front and back panels, depending on the pack size. In addition, manufacturers will be required to ensure that, on a brand-by-brand basis, all eight health messages appear simultaneously, with half of their packaging containing a warning in black text on a white background and the other half in white text on a black background. The text of the eight health messages appear in the table, and a mock-up of one of the warnings appears in the figure.

As can be seen, the Canadian government chose to simultaneously change four variables: size, location, colour, and content. This was based upon the scientific literature, which indicates that changing any one of these parameters will initially bring the messages out of the noise. $^{6-9}$

Of particular interest is the study by Bhalla and Lastovicka, which examined the impact of changing cigarette warning message content and format in cigarette advertisements in the US. ${ }^{9}$ These authors concluded that "changing warning message content was as effective as no content change at all, in the absence of format change" and that "the more severe the departure of the format form 
Figure Sample mock-up of one of the proposed Canadian health warnings (actual size). Where the word "Cigarettes" is shown, actual brand names and/or trademarks would continue to appear.
Table New Canadian health messages on cigarette packages (effective 12 August 1994)

\section{Health message}

Cigarettes are addictive

Tobacco smoke can harm your children

Cigarettes cause fatal lung disease

Cigarettes cause cancer

Smoking during pregnancy can harm your baby

Smoking can kill you

Tobacco smoke causes fatal lung disease in non-smokers
Cigarettes cause strokes and heart disease
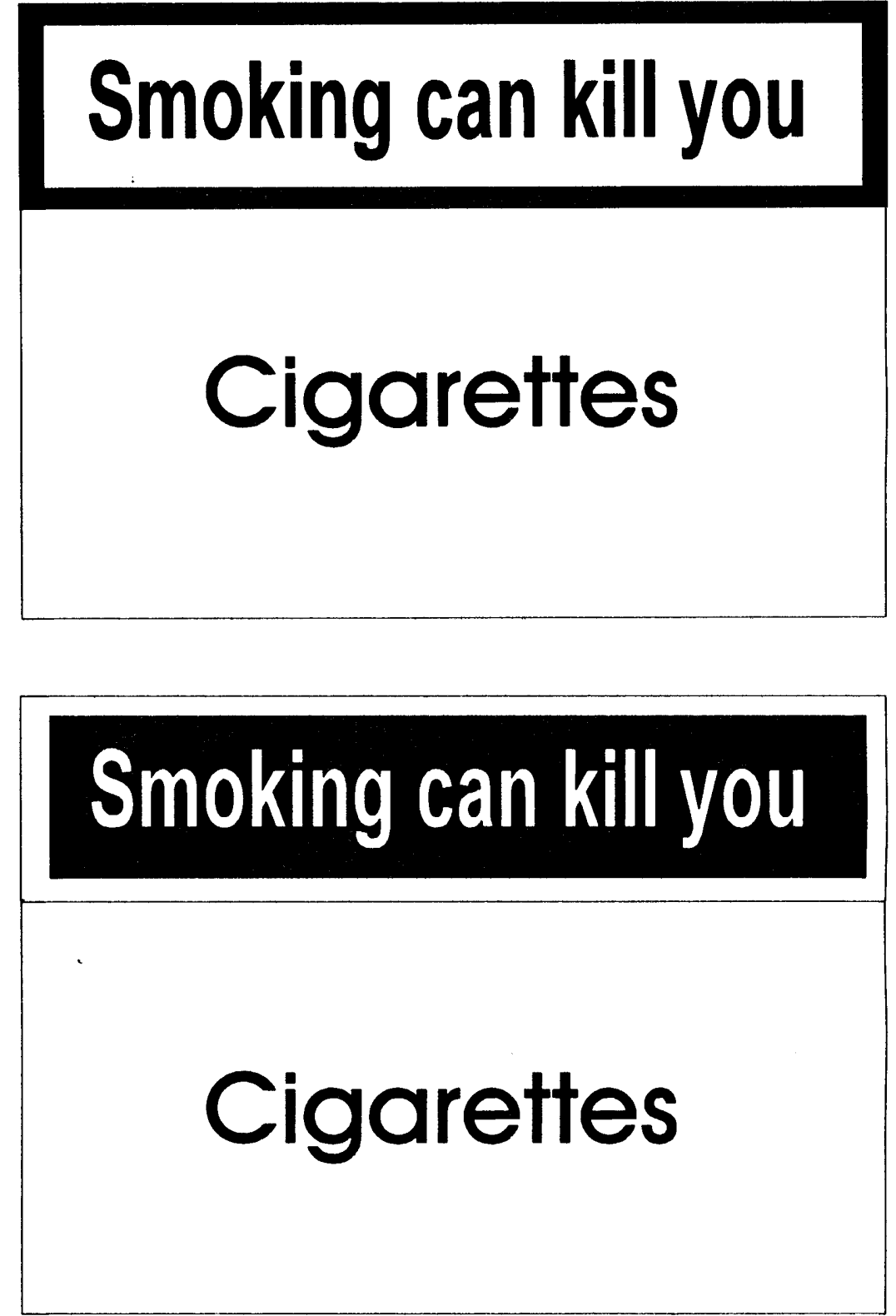

from the existing format and the less textual the advertising context, the greater the potential effect". ${ }^{9}$

This is in contrast to the findings of Popper et al, who concluded that changing the colour of the message or increasing the size of the message by $40 \%$ did not result in increased awareness. ${ }^{10}$ Closer examination of this work indicates that the changes were relatively minor - a change in type size from 10 to 14 point and a change in colour from white to grey. ${ }^{10}$ Indeed, it could have been easily predicted that changing the type size of the text without changing the message or the size occupied by the message would have had no noticeable effect.

Fischer et al conclude in their article that the present legislative approach to mandated health warning messages has failed as a public health policy. ${ }^{1}$ Indeed, new approaches are required, but mandated health messages should not be abandoned. As shown above, the Canadian experience suggests that mandated health messages on packages are a useful, effective, and inexpensive way of reaching the smoker.

The Canadian model has also provided another surprise. The Tobacco Products Control Act allowed outdoor advertising to continue until 1 January $1991 .{ }^{2}$ Existing signs could remain in place, but new signs had to have a health message that occupied $20 \%$ of the top portion of the sign. Almost immediately, billboards began disappearing. Cigarette manufacturers, after previewing new billboards, were unwilling to risk the impact of such large health messages on their sales. Indeed, one representative you see is a big warning that says 'Smoking causes cancer'. You've got to see it to understand. It's just a feeling." "1i This, then, is the "line in the sand" for Canadian cigarette manufacturers: $20 \%$ at the top of the billboard.

In Canada, a comprehensive programme consisting of an advertising ban, large health messages on packages, increased taxes, and vigorous health promotion activities has resulted in spectacular declines in cigarette sales and a radical change in the marketing of tobacco products. There is no reason to suspect that a similar programme in the US would have a different result. Indeed, if Fischer et al's targeted approach to health warning messages is adopted, the results could be even more spectacular.

Tobacco Products Section,

MURRAY J KAISERMAN

Product Safety Division, Environmental Health

Directorate, Ottawa, Ontario, Canada described the new billboards this way: "The first thing 
1 Hill D. Australia's new health warnings on cigarette packaging. Tobacco Control 1992; 1: 92-4.

2 The Tobacco Products Control Act. RSC C20; 1988.

3 Saine Marketing. Readability study on the warning sentence on cigarette packs. Montreal: Saine Marketing, 1989.

4 packs. Montreal: Saine Marketing, 1989. illiam Leiss \& Associates Ltd. Evaluation report on the "Readability study on the warning sentence on cigarette packs". Vancouver, British Columbia: William Leiss \& Associates, 1989.

5 Tandemar Research Inc. Tobacco health warning messages, inserts and toxic constituent information study. Final report. Toronto, Ontario: Tandema Research Inc, 1992.

6 Lehto MR, Miller JM. Warnings, vol I (Fundamentals, design and evaluation methodologies). Ann Arbor, Michigan: Fuller Technical Publications, 1988.
7 Centre for Behavioral Research in Cancer. Health warning and content labelling on tobacco products. Victoria, Australia: Centre for Behavioral Research in Cancer, Anti-Cancer Council of Victoria, 1992 .

8 Adams AS, Hsu L. The coding of symbols signs. Hazard Prev 1981 (March/April): 5-7.

9 Bhalla G, Lastovicka JL. The impact of changing cigarette warning message content and format. Adv Consumer Res 1984; 11: 305-10.

10 Popper ET, Murray KB. Communication effectiveness and formal effect on in-ad disclosure of health warnings. $\mathcal{F}$ Public Policy Marketing 1989; 8: $109-23$

11 Strauss $M$. Two tobacco companies to end ads. The Globe and Mail (Toronto), 29 March 1989: B-1. 